\title{
DERECHOEIECTORAL
}

\section{Representatividad de minorías a la luz del artículo 95 constitucional}

\section{f}

Francinie Cubero de la Vega*

DOI 10.35242/RDE_2019_28_4

Nota del Consejo Editorial

Recepción: 2 de mayo de 2019.

Revisión, corrección y aprobación: 29 de mayo de 2019.

Resumen: El artículo 95 de la Constitución Política costarricense establece en su inciso 6 la garantía de representatividad de minorías. Entendiendo "representatividad" como la conversión de votos electorales en poder político (diputaciones), se pretende analizar las condiciones actuales de representatividad política con la que cuentan grupos minoritarios. Para lo anterior, y una vez desarrollados los conceptos básicos de referencia, se procede a realizar un análisis con datos estadísticos, inicialmente para determinar grupos minoritarios y la representación de estos en los periodos legislativos del 2010 al 2018. El análisis de dichos datos pretende demostrar la casi inexistente participación de minorías en el congreso, así como las consideraciones de actores importantes como el Tribunal Supremo de Elecciones y la Sala Constitucional de la Corte Suprema de Justicia, respecto del cumplimiento del referido artículo 95 inciso 6) constitucional. Las conclusiones ofrecen una serie de propuestas prácticas en relación con lo estudiado.

Palabras clave: Representación política / Sistema de elección de diputados / Minoría legislativa / Partidos minoritarios / Grupos minoritarios / Grupos étnicos.

Abstract: Article 95 of the Costa Rican Political Constitution establishes in clause 6 the guarantee of representation of minorities; understanding "representation" as the conversion of electoral votes into political power (congress member), the goal is to analyze the current conditions of political representation specifically in minority groups. For that, and once basic reference concepts have been analyzed, an analysis with statistical data is carried out, initially to determine minority groups and their representation in the National Congress from 2010 to 2018 periods. The analysis of these data, will demonstrate the almost non-existent participation of minorities in congress, as well as the considerations of important actors such as the Supreme Electoral Tribunal, The Constitutional Chamber of the Supreme Court of Justice with respect to compliance with the aforementioned article 95 clause 6) constitutional. The conclusions offer a series of practical proposals in relation to what has been studied.

Key Words: Political representation / System of election of Congress members / Legislative minority / Minority parties / Minority groups / Ethnic groups.

\footnotetext{
* Costarricense, abogada, correo francinie@gmail.com. Licenciada en Derecho, especialista en Derecho Notarial y Registral y master en Gerencia de Proyectos por Universidad Latinoamericana de Ciencia y Tecnología; mediadora y conciliadora certificada por el Centro de Arbitraje y Mediación del Colegio de Abogados y Abogadas de Costa Rica, profesora universitaria, actualmente abogada asistente de la Procuraduría General de la República en Área de la Función Pública, con amplia experiencia en instrucción de procedimientos administrativos.
} 


\section{DERECHOELECTORAL}

\section{INTRODUCCIÓN}

El presente artículo tiene como propósito analizar las condiciones actuales de representatividad política con la que cuentan grupos minoritarios, y las garantías constitucionales para asegurar su participación política, según reza el artículo 95 de la Constitución Política costarricense.

La primera parte del artículo se centrará en comentarios generales respecto de minorías y representatividad para, posteriormente, entrar a determinar cuáles son los grupos considerados minoritarios y que hayan contado con representatividad legislativa en los periodos del 2010 al 2018. Para lo anterior, se procederá a analizar la conformación de la Asamblea Legislativa en dichos periodos, y se hará una comparación con los datos del Instituto Nacional de Estadísticas y Censos (INEC) para analizar si existen o no parámetros de representatividad únicamente respecto de diputaciones.

Finalmente, se determinarán las garantías constitucionales de participación con las que cuentan estos grupos minoritarios, y si estas tienen una incidencia positiva o negativa en su participación y representatividad.

\section{CONSIDERACIONES GENERALES DE MINORÍAS Y REPRESENTATIVIDAD EN LA APLICACIÓN DE PRINCIPIOS ELECTORALES}

Los principios electorales de equidad y democracia permiten a los ciudadanos su participación democrática procurando que se dé en igualdad de condiciones. Sobre esto, el Tribunal Supremo de Elecciones, en su voto 2759-E-2001 de las 13:00 horas del 26 de diciembre del 2001, indicó:

El derecho a la igualdad, junto con el derecho a la libertad, conforman el contenido básico del concepto democracia establecido por el artículo $1 .^{\circ}$ de la Constitución Política como sistema fundamental de nuestra organización política. La democracia, entre otras consecuencias, integra al ciudadano en la comunidad política, quien, mediante su participación activa en los procesos electorales, decide la organización del Estado y el nombramiento de las autoridades que lo representan.

El anterior extracto refiere a la necesidad de participación ciudadana con el fin de robustecer la democracia del país; siendo este el pilar principal de nuestro Estado democrático, conlleva que se convierta en poder político por 


\section{DERECHO EIECTORAL}

medio de la representatividad. Por ello, es menester entrar a analizar generalidades referentes a minorías y su representación política, con el fin de tener una perspectiva adecuada a la hora de analizar los datos suministrados.

\section{a. MinORÍAs}

En su artículo, Enith Pinedo (2010) hace dos distinciones conceptuales de minorías; por un lado, refiere al concepto dado por Guillaumin, citado por González Martín (2001, p. 72), apuntando que por grupos minoritarios "entenderemos no aquellos que serían forzosamente menores en número sino más bien aquéllos que en una sociedad están en estado de "menor poder", sea éste económico, jurídico, político ...". Por otro lado, refiere a la calidad de minorías que el Institute for Democracy and Electoral Assistance (IDEA) ha dado a dichos grupos, para generar una diferenciación en los mecanismos con propósito de asegurar la representación política.

Por su parte, Román Corona (2006) realiza un amplio análisis conceptual de minorías, tanto doctrinario como normativo; concluye que si bien no hay una definición conceptual universal, esta tiene en común una serie de elementos objetivos y subjetivos: la autoidentificación como minoría. Dentro de los elementos objetivos se ubica a aquellos externos al grupo o colectivo humano, los que se pueden entender como:

- Grupo o colectivo humano

- Inferioridad numérica

- Presencia de rasgos característicos comunes (lengua, religión, etnia, costumbres, etc.)

- Dependencia, no dominación o vulnerabilidad del grupo

Las participaciones minoritarias en democracias pluraristas permiten no solo oportunidades de representación de grupos usualmente diversos de la mayoría del país, sino que también permiten una suerte de control y contrapeso sobre aquellos que son mayoritarios, con el fin de evitar una superposición indiscriminada de estos, pero sin recaer en obstrucciones infundadas. La participación conjunta de mayorías y minorías debe ser la búsqueda de equilibrio entre posiciones. 


\section{DERECHO EIECTORAL}

Si bien en Costa Rica no existe una forma especial de elección de representantes minoritarios como en adelante se ahondará, la Red de conocimiento $\mathrm{ACE}^{1}$ hace un resumen de cómo en otras latitudes se fomenta la participación y representación minoritaria de una manera más activa. Al respecto, ejemplifica la implementación de escaños reservados para minorías étnicas o religiosas como por ejemplo: Colombia (comunidades negras), Croacia (minorías húngaras, italianas, checas, eslovacas, rutenias, ucranianas, alemanas y austriacas), la India (tribus y castas), Jordania (cristianos y circasianos), Níger (tuareg), Nueva Zelandia (maorí), Pakistán (minorías no musulmanas), Palestina (cristianos y samaritanos), Samoa (minorías no indígenas), Eslovenia (húngaros e italianos), Taiwán (comunidad aborigen) y de manera reciente Irak (cristianos, yazidis, sabeos y shabaks).

En el caso de Colombia, se dispone por ley² la manera de elección de escaños en circunscripciones especiales, reservándose dos escaños para comunidades negras, una para comunidades indígenas, una para minorías políticas $^{3}$ y una para ciudadanos residentes en el exterior. Para el caso de los indígenas, indica González (2016) que debe demostrarse, mediante certificación del Ministerio del Interior, la pertenencia a una comunidad indígena y el ejercicio como autoridad o haber sido autorizado.

Para el presente artículo, entenderemos minorías como un grupo autoidentificable o autopercibido con rasgos características comunes como raza o etnia, edad y discapacidad.

\footnotetext{
1 ACE, Red en línea de conocimientos electorales. Recuperado de http://aceproject.org/acees/topics/es/esd/esd06/default [consultado 17 febrero 2019].

2 Ley 649 del 27 de marzo del 2001 (por la cual se reglamenta el artículo 176 de la Constitución Política de Colombia)

3 Ibídem, artículo 4: Candidatos de las minorías políticas. Podrán acceder a una curul por la circunscripción especial para las minorías políticas, los movimientos o partidos políticos: a) Que hubiesen presentado candidatos a la Cámara de Representantes como mínimo en un 30\% de las circunscripciones territoriales; b) Que no hubiesen obtenido representantes en el Congreso Nacional, y c) Que su votación mayoritaria en un mismo departamento o circunscripción territorial sea menos del $70 \%$ de la sumatoria de su votación en todo el país. La curul corresponderá al partido o movimiento político que, cumpliendo con los requisitos, de los literales anteriores obtenga la mayor votación agregada en todo el país. La lista a la cual se le asignará la curul será la conformada por las cabezas de lista de mayor a menor votación de las inscritas por el respectivo partido o movimiento en todo el territorio nacional.
} 


\section{DERECHOELECTORAL}

\section{b. Representatividad}

La representatividad es la capacidad de actuar en nombre de una persona, o en términos electorales, de los electores. Para Picado "la representatividad se refiere tanto a la proporcionalidad del sistema como a la vinculación entre la ciudadanía y sus gobernantes" (2008, p. 5). Para esto, el sufragio es el método para lograr dicha representatividad.

Si bien el poder político se encuentra representado en la Asamblea Legislativa o Parlamento, no por ello puede afirmarse que sea efectivamente representativo de los votos emitidos. Sobre este aspecto, Ilama la atención González (2014) al citar a Duverger en el sentido de que la sensación de representación tiene una importancia considerable, de ahí que apoye la tesis de que cuanta mayor proporcionalidad entre representante-representado tanta mayor representatividad.

\section{ANÁLISIS DE GRUPOS MINORITARIOS Y SU REPRESENTACIÓN EN LA Asamblea LegisLativa de LOS PERIOdos de 2010 AL 2018}

En el presente acápite, se tomarán datos estadísticos obtenidos del INEC con el propósito de hacer un análisis de los grupos minoritarios del país. Para contar con datos reales, se tomó el último censo realizado en el año 2011 para la obtención de los cálculos estadísticos, así como la Encuesta Nacional de Hogares de dicho año. En razón de lo anterior, y dado que no se cuenta con los datos estadísticos para los efectos, se omite la cuantificación de la población LGTBI en el presente artículo, con la salvedad de que en términos generales es una minoría.

Por otro lado, se revisarán los datos de los diputados electos en los periodos 2010-2014, 2014-2018, y 2018-2022 para identificar si existe representación de grupos minoritarios y en qué grado. Se aclara que no se procedió con el estudio de cada partido político inscrito en dichos periodos para precisar los fines y objetivos y si están ligados con la participación de grupos minoritarios, pero se presta la oportunidad a futuro de hacer un estudio comparativo sobre dichos elementos.

\section{a. Datos estadísticos DE MINORÍAS}

De conformidad con la tabla 1, para el 2011 se contaba con una población total de 4301712 personas (100\%); de estas, según la 


\section{DERECHO EIECTORAL}

autoidentificación étnica-racial, la población indígena correspondía a $104143(2,4 \%)$, la negra o afrodescendiente correspondía a 45228 $(1,1 \%)$, la mulata a $289209(6,7 \%)$, la china a $9170(0,2 \%)$; los blancos o mestizos representan $3597847(83,6 \%)$ de la población. Personas que no se autoidentificaron con ninguna etnia 124641 (2,9\%), mientras que $36334(0,8)$ corresponde a otros y $95140(2,2 \%)$ como no declarado.

De los anteriores datos se rescata que la mayoría de la población se identifica como blanco o mestizo en un $83,6 \%$; mientras que las restantes cuatro etnias como mulatos, indígenas, negros o afrodecendientes o chinos: en total, $10,4 \%$ de la población del país.

Tabla 1

Autoidentificación étnica-racial Censo 2011

\begin{tabular}{lrc}
\hline \multicolumn{1}{c}{ Grupo } & \multicolumn{1}{c}{ Cantidad } \\
\hline Indígenas & 104143 & $2,4 \%$ \\
Negro( a) o & 45228 & $1,1 \%$ \\
Afrodescendiente & 289209 & $6,7 \%$ \\
Mulato(a) & 9170 & $0,2 \%$ \\
Chino(a & 3597847 & $83,6 \%$ \\
Blanco(a) o Mestizo(a) & 36334 & $2,9 \%$ \\
Otro & 124641 & $0,8 \%$ \\
Ninguna & 95140 & $2,2 \%$ \\
No Declarado & $\mathbf{4 3 0 1 7 1 2}$ & $\mathbf{9 9 , 9 \%}$ \\
\hline Población total &
\end{tabular}

Nota: Elaborado con datos del INEC, Autoidentificación étnica-racial Censo 2011.

De acuerdo con datos obtenidos de la página del INEC para la población por años calendario, según sexo y grupos especiales de edades; haciendo una proyección únicamente en la población, el incremento anual de la población del 2011 al 2018, sería de 58760 aproximadamente como se evidencia en la figura 1. 


\section{DERECHOELECTORAL}

Realizando una suerte de analogía con los datos estudiados previamente, el aumento proporcional de las referidas minorías incrementaría en un $10 \% 4$.

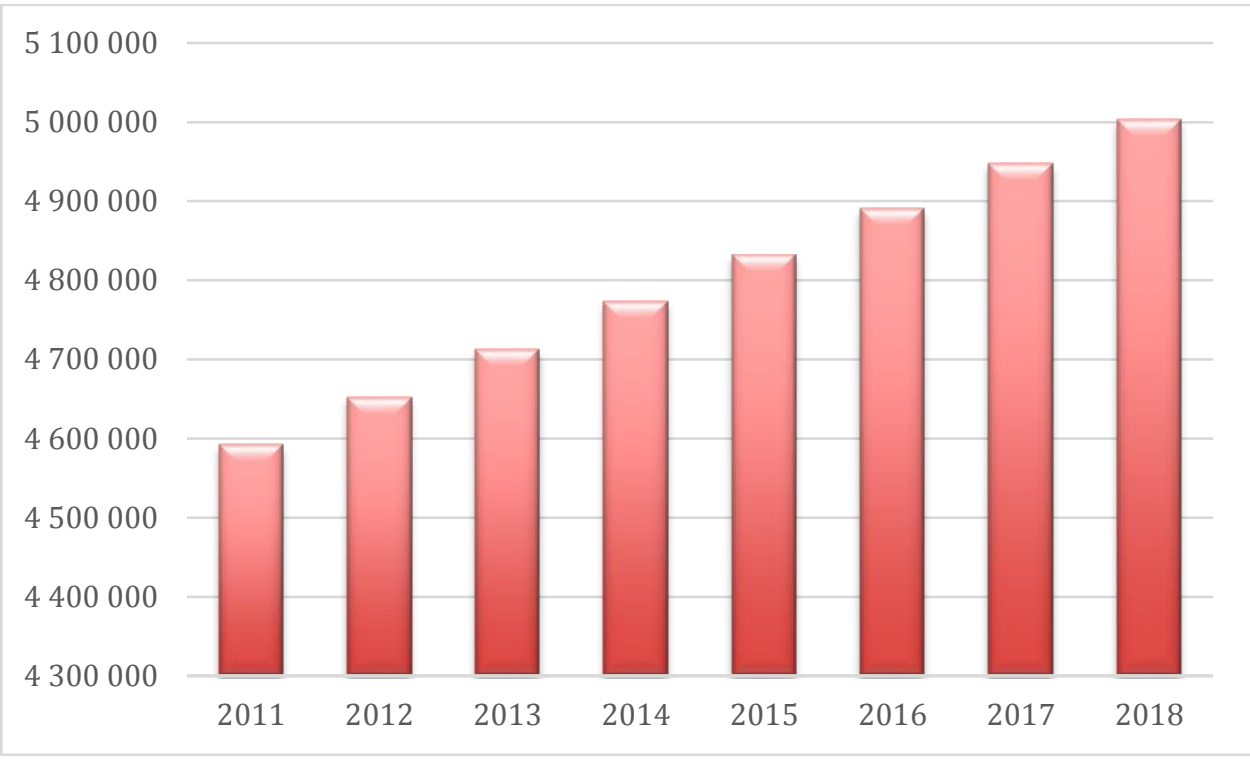

Figura 1. Proyección del incremento anual de la población del 2011 al 2018. Elaborado con datos del INEC, población por años calendario, según sexo y grupos especiales de edades, Censo 2011.

En el caso de las personas con discapacidad, según se evidencia en la tabla 2, para el 2011 se contaba con una población total de 4301712 personas (100\%); de estas, la población con discapacidad se dividió de la siguiente forma: discapacidad para ver con los anteojos o lentes puestos, 251464 (5,85\%); para oír, 70709 (1,64\%); para hablar, $29413(0,68 \%)$; para caminar o subir las gradas, $40380(3,26 \%)$; para utilizar brazos o manos, $48859(1,14 \%)$. Del tipo intelectual corresponde a $35416(0,82 \%)$; del tipo mental, a $26971(0,63 \%)$. Por otro lado, las personas que no tienen ninguna discapacidad equivalían a 3848863 (89,47\%).

Con base en los anteriores datos se rescata que, de la totalidad de la población en el 2011 , un $14,02 \%$ correspondía a personas con algún grado de discapacidad.

\footnotetext{
${ }^{4}$ Datos no son exactos al no contar con información actualizada por parte del INEC, por lo que se basa en un cálculo proyectado de forma proporcional.
} 


\section{DERECHO ELECTORAL}

Tabla 2

Población con discapacidad

\begin{tabular}{lrc}
\hline Tipo de discapacidad & Cantidad & Porcentaje \\
\hline Para ver aún con los anteojos o lentes & 251464 & $5,8 \%$ \\
puestos & 70709 & $1,64 \%$ \\
Para oír & 29413 & $0,68 \%$ \\
Para hablar & 140380 & $3,26 \%$ \\
Para caminar o subir gradas & 48859 & $1,14 \%$ \\
Para utilizar brazos o manos & 35416 & $0,82 \%$ \\
Del tipo intelectual & 26971 & $0,63 \%$ \\
Del tipo mental & 3848863 & $89,47 \%$ \\
No tiene ninguna discapacidad & 4301712 & $99,9 \%$ \\
\hline Población total
\end{tabular}

Nota: Elaborado con datos del INEC, población con discapacidad, Censo 2011.

Por su parte, en el caso de adultos mayores tenemos que la población total según la Encuesta Nacional de Hogares (ENAHO) correspondía 529 627, que porcentualmente para el año 2011, de acuerdo con la población total (4 301 $712)$, representaba un $12,31 \%$ de la población.

Este este grupo se subdivide en grupos etarios de 60 a 64 conformado por 165072 (31\%); por su parte el grupo de 65 a 74 correspondía a 205944 (39\%); mientras que el grupo de 75 años y más, a 158611 (30\%), como puede observarse en la tabla 3.

Tabla 3

Población de 60 años y más

\begin{tabular}{l|ccr}
\hline \multirow{2}{*}{ Población total } & \multicolumn{4}{c}{ Grupos de edad } \\
\cline { 2 - 4 } & $\mathbf{6 0}$ a $\mathbf{6 4}$ & $\mathbf{6 5}$ a $\mathbf{7 4}$ & $\mathbf{7 5}$ y más \\
\hline $\mathbf{5 2 9} \mathbf{6 2 7}$ & 165 & 205944 & 158611 \\
$\mathbf{1 0 0 \%}$ & $31 \%$ & $39 \%$ & $30 \%$ \\
\hline Nota: Elaborado con datos del & INEC, población adulta mayor, \\
ENAHO 2011.
\end{tabular}




\section{DERECHOELECTORAL}

\section{b. Datos ESTADÍSTICOS DE DiPUTADOS Y DIPUTADAS PERIOdOS 2010 AL 2018}

En el presente apartado, se revisarán los resultados de los diputados y las diputadas electos en los periodos 2010-2014, 2014-2018, y 2018-2022 para identificar si dentro de estos existe representación de grupos minoritarios y en qué grado. Se hace la salvedad de que no se realiza estudio de cada partido político para analizar si en su estructura interna o en los fines del partido existe dentro de los objetivos principales la representación de minorías; salvo en el caso puntual que se señalará.

\section{i. Periodo 2010-2014}

Mediante resolución n.0 1820-E11-2010 de las 10:40 del 17 de marzo del 2010, se declararon constitucionalmente electos diputados a la Asamblea Legislativa, para el período constitucional comprendido entre el primero de mayo de dos mil diez y el treinta de abril de dos mil catorce. En la tabla 4 se detalla la asignación de curules por cada partido político.

Tabla 4

Diputados electos para el periodo 2010-2014, según partido político

\begin{tabular}{lc}
\hline Partido político & $\begin{array}{c}\text { Total de } \\
\text { diputaciones }\end{array}$ \\
\hline Accesibilidad Sin Exclusión & 4 \\
Acción Ciudadana & 11 \\
Frente Amplio & 1 \\
Liberación Nacional & 24 \\
Movimiento Libertario & 9 \\
Renovación Costarricense & 1 \\
Restauración Nacional & 1 \\
Unidad Social Cristiana & 6
\end{tabular}

Nota: Elaboración propia con datos del TSE, Declaración de diputados periodo 2010-2014.

Se llama la atención en dicho periodo que el Partido Accesibilidad sin Exclusión (PASE), abiertamente conocido su propósito de representar personas con discapacidad, obtuvo cuatro diputaciones en todo el país; por otro lado, si bien los partidos Renovación Costarricense y Restauración 


\section{DERECHO EIECTORAL}

Nacional, al ser cristianos podrían considerarse una minoría según la agrupación y semejanzas religiosas, no serán tomados como tales por no tener datos estadísticos en estos momentos para realizar tal afirmación. El posterior análisis comparativo se limitará a los datos y grupos estudiados previamente.

Según la biblioteca de la Asamblea Legislativa, en el periodo 2010-2014 no se eligieron personas afrocostarricenses, por lo que es uno de los periodos sin representación de tal grupo.

De la totalidad de 57 diputaciones, solamente 4 corresponden a un partido destinado a personas con discapacidad, lo que corresponde a un 2,28\% de la totalidad del plenario. Cabe apuntar que de estas cuatro curules, solo una fue ocupada por un diputado con una discapacidad visual.

\section{ii. Periodo 2014-2018}

Mediante resolución n.0 0830-E11-2014 de las 10:00 del 03 de marzo del 2014, se declararon constitucionalmente electos diputados a la Asamblea Legislativa, para el período constitucional comprendido entre el primero de mayo de dos mil catorce y el treinta de abril de dos mil dieciocho según los datos de la tabla 5 .

Tabla 5

Diputados electos por partido, elecciones febrero 2014

\begin{tabular}{lc} 
Partido político & Total de diputaciones \\
\hline Accesibilidad Sin Exclusión & 1 \\
Acción Ciudadana & 13 \\
Alianza Democrática Cristiana & 1 \\
Frente Amplio & 9 \\
Liberación Nacional & 17 \\
Movimiento Libertario & 4 \\
Patria Nueva & 1 \\
Renovación Costarricense & 2 \\
Restauración Nacional & 1 \\
Unidad Social Cristiana & 8 \\
\hline
\end{tabular}

Nota: Elaborado con datos del TSE, Declaración de diputados periodo 2014-2018. 


\section{DERECHO EIECTORAL}

En esta ocasión, disminuye la cantidad de diputados electos por el PASE, quien solamente ocupa una curul; sin embargo, se rescata la elección de dos mujeres afrodescendientes en los partidos Acción Ciudadana y Liberación Nacional, Epsy Campbell Barr y Maureen Clarke Clarke, respectivamente.

De la totalidad de 57 diputaciones, solamente 1 representa a un partido destinado a personas con discapacidad y 2 refieren a personas afrodescendientes, lo que equivale a un $1,71 \%$ de la totalidad del plenario.

\section{iii. Periodo 2018-2022}

La tabla 6 muestra los diputados electos para el período constitucional comprendido entre el primero de mayo de dos mil dieciocho y el treinta de abril de dos mil veintidós, declarado mediante resolución n. ${ }^{0}$ 1230-E11-2018 de las 11:00 del 27 de febrero del 2018.

Tabla 6

Diputados electos por partido político, elecciones febrero de 2018

\begin{tabular}{lc} 
Partido político & Total de diputaciones \\
\hline Acción Ciudadana & 10 \\
Frente Amplio & 1 \\
Integración Nacional & 4 \\
Liberación Nacional & 17 \\
Republicano Social Cristiano & 2 \\
Restauración Nacional & 14 \\
Unidad Social Cristiana & 9 \\
\hline
\end{tabular}

Nota: Elaborado con datos del TSE, Declaración de diputados periodo 2018-2022.

Dada la coyuntura particular en las pasadas elecciones, se desaparece la participación del PASE en la Asamblea Legislativa, y solamente hay una persona afrodescendiente electa, en el partido Restauración Nacional, el diputado Eduardo Newton Cruickshank Smith. 


\section{DERECHO EIECTORAL}

Finalmente, de la totalidad de las 57 diputaciones, solamente fue elegido 1 diputado afrodescendiente, esto significa un $0,57 \%$ de la totalidad del plenario.

\section{Comparación de datos estadísticos}

En la figura 2, se hace una comparación de los partidos políticos electos y los distintos movimientos que se han realizado en los tres periodos de estudio. Entre los partidos con mayor cantidad de diputados electos se rescatan Liberación Nacional, Acción Ciudadana, Unidad Social Cristiana, y en el último periodo, Restauración Nacional.

De los anteriores, solamente Liberación Nacional, Acción Ciudadana y Restauración Nacional han elegido como diputados a personas afrodescendientes, y ninguno con discapacidad notable; en este caso, y según la tendencia del partido, el PASE eligió en el periodo 2014-2018 al diputado Oscar López, quien cuenta con una discapacidad visual.

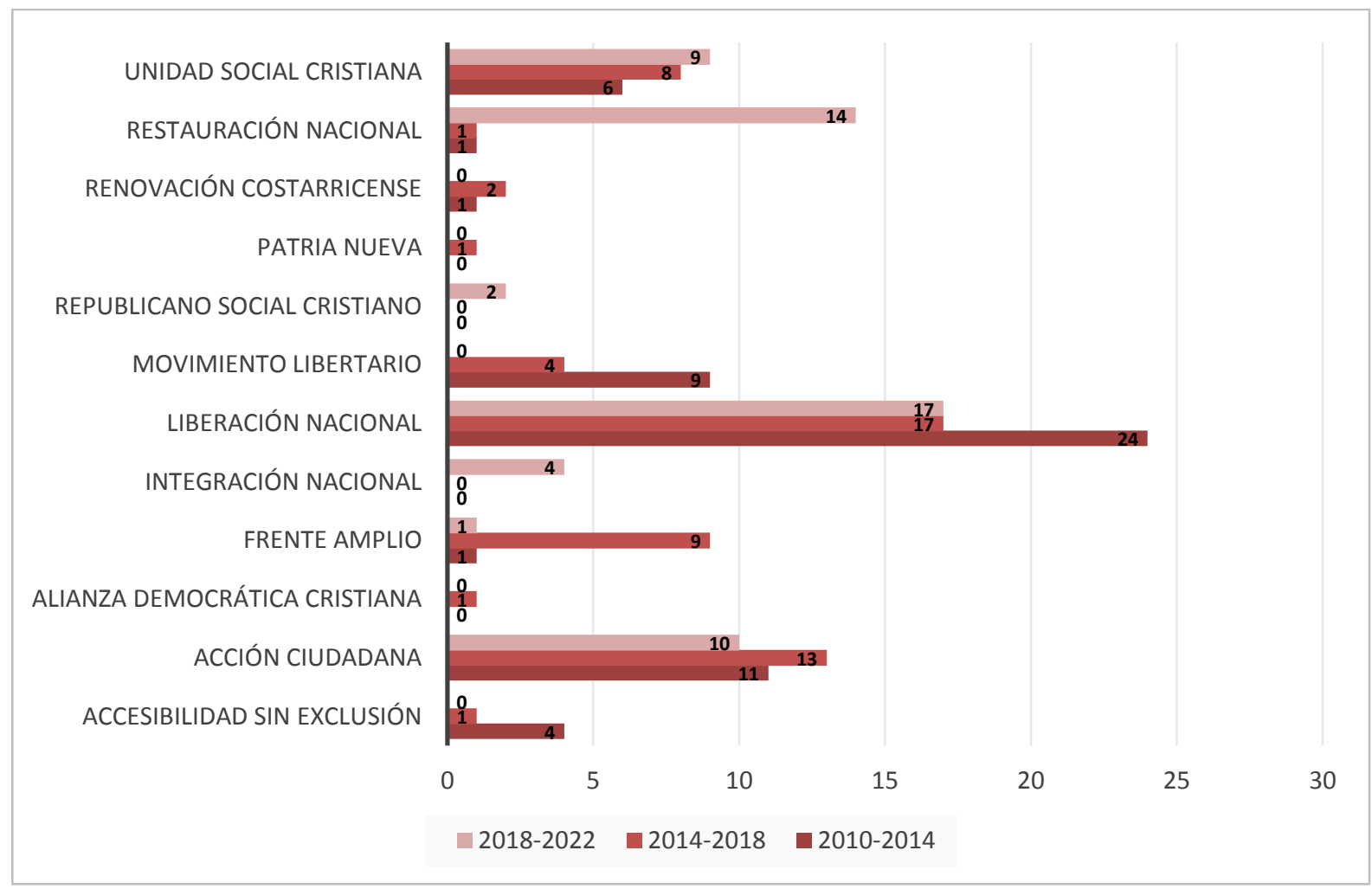

Figura 2. Diputaciones electas en periodos 2010 al 2014, 2014 al 2018, 2018 al 2022. Elaborado con datos del TSE. 


\section{DERECHO EIECTORAL}

Por su parte, en la figura 3, se brinda un resumen de la cantidad de diputados minoritarios, con la salvedad de que, en el caso de "discapacidad" se incluye a los diputados que forman parte del PASE, aunque no tengan por sí mismos una discapacidad, pero defienden su representación en beneficio de dicha población y de los adultos mayores. Por otro lado, al no existir datos estadísticos para recuperar la información y esta cambia año con año, no se colocan datos sobre diputados y diputadas mayores de 60 años; pero sin embargo, se contabilizarán para efectos de las proyecciones que se dirán.

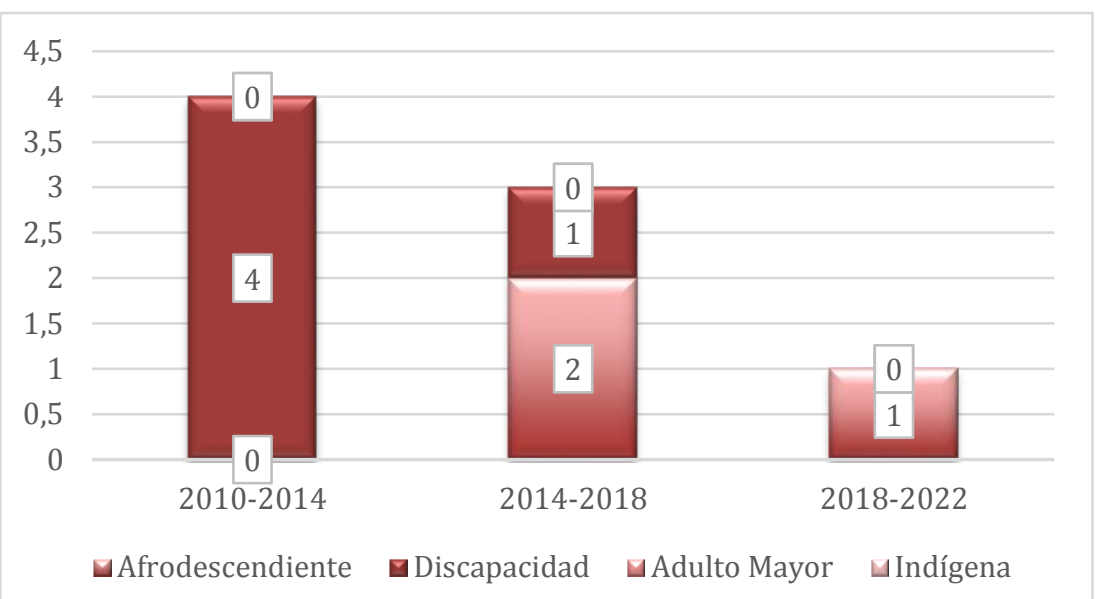

Figura 3. Diputaciones electas en periodos 2010 al 2014, 2014 al 2018, 2018 al 2022. Elaborado propia con datos del TSE.

Dado que el artículo 106 de la Constitución Política establece el número de diputados para representar a la nación (57), quiere decir que para el $2011^{5}$, para una población de 4301676 , cada diputado y diputada representa a 75468 personas por periodo, lo cual corresponde al 1,75\% de la población.

Para el año 2018, para una población proyectada de 5003 402, la representación por cada diputado y diputada corresponde a 87779 personas, manteniéndose el mismo porcentaje proporcional de la población $(1,78 \%)$. Se puede afirmar que cada diputado representa a menos del $2 \%$ de la población.

En el caso de las minorías étnicas del país, estas corresponden al 10,4\% de la totalidad del país (447 750), de acuerdo a los datos del Censo 2011, lo

\footnotetext{
${ }^{5}$ Según los datos suministrados por el INEC de acuerdo con la última información estadística del Censo 2011, la población total es de 4301712 .
} 


\section{DERECHO EIECTORAL}

que equivale a 5,93 escaños. Sin embargo, si realizamos una subdivisión de las etnias estudiadas, específicamente en las indígenas y negra o afrodescendiente; en el caso de la primera, su cantidad de población para el 2011 era de 104 143, esta cifra equivale a un 2,4\% de la población, y con ello le correspondería, al menos, un escaño para acreditar su representatividad. En cuanto a los negros o afrodescendientes, su población de 45228 personas, corresponde a poco más de la mitad del número mínimo de representación legislativa, lo que significa un $1 \%$ de la población $y$, por ende, no tiene la cantidad de población necesaria para reclamar un escaño.

Por su parte, la minoría por discapacidad es el 14,02\% (603 212) de la totalidad del país, esto equivale a 7,99 escaños. Finalmente, la minoría de tercera edad es $12,31 \%$ (539 627) de la totalidad, correspondiente a 7,15 escaños.

De conformidad con la figura 3, evidentemente que no se ha dado una representatividad ni siquiera cercana a lo respectivo según la cantidad de población a la que representa cada diputado. Véase que, incluso, si hipotéticamente la cantidad de escaños para minorías en su conjunto corresponde al promedio de $12,24 \%{ }^{6}, 526529$ personas, tendrían 6,97 escaños. De igual manera, realizando los anteriores cálculos con la proyección de población para el año 2018 (5 003 402), no genera ningún cambio sustancial, dado que se proyecta el aumento de la población minoritaria en un $10 \%$ aproximadamente, como fue referido respecto de la figura 2.

Según dichos datos, lo más cercano que se ha estado de una representación minoritaria proporcional ha sido en el periodo 2010-2014, la cual disminuyó considerablemente en los siguientes períodos, tal así que para el periodo 2018-2022, solamente existe un diputado de un grupo considerado minoritario. No podría adentrarse en el presente estudio en los motivos de dicha disminución, así como tampoco afirmarse que se deba a una falta de participación; lo cierto es que, de los resultados analizados, se puede concluir que no existe en el congreso una representatividad de minorías, al menos en los periodos estudiados.

\footnotetext{
${ }^{6}$ Correspondiente al promedio de las sumas de todos los porcentajes de minorías estudiados (étnica, discapacidad y etaria).
} 


\section{DERECHO ELECTORAL}

\section{Garantías Constitucionales para minorías}

El artículo 95 de la Constitución Política establece:

La ley regulará el ejercicio del sufragio de acuerdo con los siguientes principios:

(...)

6.- Garantías de representación para las minorías; (...)

Según consideraciones del Tribunal Supremo de Elecciones, visibles en Acta n. ${ }^{\circ}$ 85-2014 de las 09:00 del cinco de agosto del 2014; al atenderse consulta legislativa del proyecto de ley de reforma al artículo 138 del Código Electoral ${ }^{7}$, se analizó que el uso del subcociente dentro de la fórmula electoral (Hare), es más proporcional al otorgar escaños a los partidos más votados. Se consideró que, si bien existe una garantía constitucional de representación de minorías, no por ello significa el otorgamiento de un cargo solamente por su participación, en cambio, la fórmula implementada les da acceso en una segunda ronda y una eventual tercera ronda, a la asignación de escaños sin exclusividad (por residuo mayor).

En ese orden de ideas, mediante los votos 7393-97 de las 15:48 del 04 de noviembre de 1997; $1234-98$ de las 16:06 del 25 de febrero de 1998; 11272-2007 de las 14:41 del 08 de agosto del 2007; y 3649-2009 de las 16:04 del 04 de marzo del 2009; todos de la Sala Constitucional de la Corte Suprema de Justicia, se discutieron acciones de inconstitucionalidad por alegadas violaciones de la representatividad de minorías, así como discriminación a partidos minoritarios. Consideraron la mayoría de los magistrados que no es lo mismo "minorías" y "partidos minoritarios", siendo necesario la votación en su favor para obtener los escaños, pues sería absurdo pretender esas garantías de representación de minorías con base en la mera participación independiente de los resultados que se produzcan en un proceso determinado. Por otro lado, y en los votos salvados de la referida jurisprudencia se considera que el sistema aplicado niega participación a quien no haya obtenido curules a razón de darles de nuevo

\footnotetext{
${ }^{7}$ Por error, la consulta se dirigió al artículo 138 del Código anterior, cuyo articulado fue derogado; dicha norma indicaba:

Artículo 138: Si quedaren plazas sin llenar por el sistema de cociente, la distribución de las mismas se hará a favor de los partidos en el orden decreciente de la cifra residual de su votación, pero incluyendo también a aquellos partidos que apenas alcanzaron subcociente, como si su votación total fuera cifra residual. Si aun quedaren plazas sin llenar, se repetirá la operación que se expresa en el aparte anterior. Este mismo sistema se aplicará en el caso de que ninguno de los partidos alcance cociente.

Lo anterior se encuentra regulado en el artículo 205 del Código Electoral vigente.
} 


\section{DERECHO EIECTORAL}

participación a quienes sí ya obtuvieron por medio de cociente ${ }^{8}$, por lo que es irracional que un grupo minoritario deba formar parte de un partido mayoritario para mantener alguna expectativa de elección.

Al respecto, si bien la forma de elección de los diputados se mantiene por medio del uso de fórmulas con la implementación de los cocientes y subcocientes, a pesar de las críticas de los votos de minorías referidos, es factible - y deseable- la representación de minorías en partidos políticos, lo que brinda la posibilidad de discutir, más allá de una reforma legislativa, si puede realizarse a manera de analogía y por parte del Tribunal Supremo de Elecciones un requerimiento partidario de una cuota minoritaria dentro de los candidatos a diputado, para la inscripción, tal como en su momento ocurrió con la aplicación de participación femenina.

\section{Conclusiones Y halLAzgos}

Tal y como se adelantó, considerando los datos estadísticos analizados a lo largo de la presente investigación, se puede concluir que en los últimos periodos electorales (2010-2014, 2014-2018, 2018-2022), no existe una representación de minorías en el congreso, al menos de la etnia indígena; de las existentes estudiadas (negra, discapacidad) no han respondido a más de un $7 \%$ de la totalidad de diputados para el periodo $2010-2014$; un $5,25 \%$ para el periodo $2014-2018$ y un $1,75 \%$ para el periodo del $2018-2020$.

Según la cantidad de población de minorías analizada, el número de escaños para minorías en su conjunto corresponde al promedio de $12,24 \%$, esto sería a 526529 personas que, a su vez, equivale a 6,97 escaños. Pese a lo anterior, y en una división aún más personalizada, específicamente tenemos que al representar a un $2,4 \%$ de la población, le correspondería, al menos, un escaño para acreditar su representatividad en el congreso, situación que no se ha dado en los periodos estudiados, y quedaría pendiente de analizar en periodos anteriores.

En el caso de los negros o afrodescendientes, su población de 45228 personas corresponde a poco más de la mitad del número mínimo de representación legislativa; ante esta situación, pareciera más bien que

\footnotetext{
${ }^{8}$ Artículo 203.- Definición de cociente y subcociente. Cociente es la cifra que se obtiene dividiendo el total de votos válidos emitidos para determinada elección, entre el número de plazas a llenar mediante dicha elección. Subcociente es el total de votos válidos emitidos a favor de un partido que, sin alcanzar la cifra cociente, alcanza o supera el cincuenta por ciento (50\%), de esta. (Código Electoral, 2009).
} 


\section{DERECHO EIECTORAL}

estamos en un caso de sobrerepresentación, al menos con los datos estudiados. Pese a lo anterior, y al no conocer de la cantidad actual de la población, podría considerarse que la representación actual es proporcional a la requerida.

En los periodos referidos, solamente en el periodo 2010-2014, se contó con la mayor cantidad de representación minoritaria (4 diputados), con la salvedad de que dicho monto se calculó, no por considerar al diputado como minoría, sino por la representación partidaria de una minoría (PASE).

Por otro lado, para los periodos 2014-2018 y 2018-2022, se dio un decrecimiento importante, pues se llegó a tener de uno a tres representantes minoritarios, cuando según el dato anterior, este correspondería realmente a casi 7 escaños de la totalidad de diputados electos; es evidente la subrepresentación de minorías en el congreso según los datos arrojados.

Si bien la Constitución Política garantiza la representación de minorías, lo cierto es que en la práctica ello no se está efectuando y sus motivos, actualmente desconocidos, son material para una futura investigación. Pese a lo anterior, es posible llegar a cumplirla por medio de una mayor participación de minorías a nivel interno partidario que, si bien no puede asegurarse con ello su representación, es una herramienta para poder cumplir el objetivo constitucional. Esto, sin embargo, es un riesgo más que una garantía, ya que depende de igual manera de la votación popular y los mecanismos partidarios internos de elección de candidatos.

\section{REFERENCIAS BIBLIOGRÁFICAS}

Aragón, M. (2005). Derecho electoral: sufragio activo y pasivo. Recuperado de http:// www.iidh.ed.cr/siii/publicaciones_Capel/Sufragio/20 Activo/20 y/20 pasivo.htm

Corona, R. (Jul.-Set., 2006). Minorías y grupos diferenciados: Claves para una aproximación conceptual desde la perspectiva internacional. Ius Revista Jurídica Digital, (22), sin paginación. Recuperado de http://www.unla.mx/iusunla22/reflexion/minorias\%20y\%20grupos\%20difernciad os.htm\#_ftn1

Costa Rica. Asamblea Legislativa. Biblioteca (2017). Consultas resueltas Diputados Afrocaribeños. Recuperado de http://www.asamblea.go.cr/sd/Documentos\% 20compartidos/Diputados\%20afrocaribe\%C3\%B1os.pdf. 


\section{DERECHO EIECTORAL}

Costa Rica. Instituto Nacional de Estadísticas y Censo [s.f.]. Grupos étnicos-raciales. Recuperado de: http://www.inec.go.cr/social/grupos-etnicos-raciales

Enciclopedia virtual [s.f.]. Mayoría y minoría. glosario de conceptos políticos usuales. Recuperado http://www.eumed.net/diccionario/definicion.php?dic=3\&def=377; consultado 17 febrero 2019

González, D. (Jul.-Set. 2014). El tamaño del Poder Legislativo como modulador del sistema electoral en la democracia representativa, el caso costarricense. Revista de Derecho Electoral, (18), 415-432. Recuperado de http://www.tse.go.cr/revista/art/18/gonzalez_fernandez.pdf

González, J. (2016) Integración de minorías étnicas por medio de los sistemas electorales. Análisis comparativo Colombia-Chile. Recuperado de https://repository.ucatolica.edu.co/bitstream/10983/3106/4/TESIS\%20FINAL\%2 0241015.pdf

Gonzalez, M. (2001). El principio de igualdad, la prohibición de discriminación y las acciones positivas. Derecho y Sociedad, (18), 71-79.

Picado, H. (Ene.-Jun., 2008). La negociación de la Reforma al Código Electoral costarricense. Revista Derecho Electoral, (5),. N5, 1-25. Recuperado de http://www.tse.go.cr/revista/art/5/picado_leon_num5.pdf

Pinedo, E. (Jul.-Dic., 2010). Las cuotas de participación electoral en Perú. Características y algunos resultados. Revista de Derecho Electoral, (10), 1-33. Recuperado de http://www.tse.go.cr/revista/art/10/pinedo_bravo.pdf

Proyecto ACE [s.f.]. Sistemas electorales. Recuperado de http://aceproject.org/acees/topics/es/esd/esd06/default

\section{Jurisprudencia}

Sala Constitucional de la Corte Suprema de Justicia (1997). Voto 7393-97 de las quince horas con cuarenta y ocho minutos del 04 de noviembre.

Sala Constitucional de la Corte Suprema de Justicia (1998). Voto 1234-98 de las dieciséis horas con seis minutos del 25 de febrero.

Sala Constitucional de la Corte Suprema de Justicia (2007). Voto 11272-2007 de las catorce horas con cuarenta y un minutos del 08 de agosto.

Sala Constitucional de la Corte Suprema de Justicia (2009). Voto 3649-2009 de las dieciséis horas con cuatro minutos del 04 de marzo. 


\section{DERECHO ELECTORAL}

Tribunal Supremo de Elecciones (2001). Voto 2759-E-2001 de las 13:00 horas del 26 de diciembre.

Tribunal Supremo de Elecciones (2010). Resolución 1820-E11-2010 de las diez horas con cuarenta minutos del 17 de marzo.

Tribunal Supremo de Elecciones (2014). Resolución 0830-E11-2014 de las diez notas del 03 de marzo.

Tribunal Supremo de Elecciones (2018). Resolución 1230-E11-2018 de las once horas del 27 de febrero. 